\title{
FLIGHT INITIATION AND DIRECTIONAL CONTROL OF BEETLES BY MICROTHERMAL STIMULATION
}

\author{
Karthik Visvanathan ${ }^{1}$, Naveen K. Gupta ${ }^{1}$, Michel M. Maharbiz ${ }^{2}$ and Yogesh B. Gianchandani ${ }^{1}$ \\ ${ }^{1}$ Department of Mechanical Engineering, University of Michigan, Ann Arbor, USA. \\ ${ }^{2}$ Department of Electrical Engineering and Computer Science, University of California at Berkeley, USA.
}

\section{ABSTRACT}

This paper presents the efforts at micro thermal stimulation to initiate the flight and control the direction of beetles. Experiments were carried out by mounting micro thermal stimulators at the base of the antenna of the Green June beetle (Cotinis nitida). Preliminary in vivo experiments with resistive micro-heaters demonstrate that the beetle generates a torque of $18 \mathrm{mN}-\mathrm{mm}$ at an estimated temperature of $43^{\circ} \mathrm{C}$ at the beetle-heater interface. These experiments utilized a micromachined resistive heater fabricated from bulk Ni foil. Additional experiments with a beetle carcass indicate that ultrasonic heating could be more effective, providing an estimated interface temperature of $43^{\circ} \mathrm{C}$ with $160 \mathrm{~mW}$ power. A circular PZT-5H disk of $3.2 \mathrm{~mm}$ diameter was used in the experiments.

\section{INTRODUCTION}

The design and development of a reliable autonomous micro air vehicle (MAV) for environment monitoring and military applications has been an important challenge for researchers over the past decade. Apart form the efforts of creating a mechanical MAV, research is underway to explore the control of insect flight, motivated by flying agility and maneuverability of insects over a significant range of mass and size.

There has been a long standing interest among the researchers to understand the factors controlling the locomotion of various species of insects. For example, the role of the motion sensitive horizontal cells in the lobila plate of the fly in controlling the yaw torque generated was discussed in [1-2]. The dependence of the flight stability during maneuvers of the hawk moth on the mechanosensory input from the antenna was demonstrated by Sane et al. [3]. The removal of the antennal flagellum of these moths was found to severely disrupt the flight stability, thereby indicating the crucial role played by the antenna in their flight. In the past there have been preliminary efforts utilizing neural stimulation to initiate and control the direction of flight in beetles [4]. An implantable flight control microsystem consisting of multiple inserted neural and muscular stimulators, a visual stimulator and a microcontroller was developed. Electroneural sensing techniques were developed to observe the neural activities and control the locomotion of freely moving cockroach in [5-6]. However,

\begin{tabular}{|l|l|} 
(a) Control Power Chemical & $\begin{array}{l}\text { Fig. 1: (a) A } \\
\text { conceptual } \\
\text { layout of various } \\
\mu \text {-systems } \\
\text { integrated with } \\
\text { the body of GJB. } \\
\text { (b) Enlarged } \\
\text { view of the head } \\
\text { of the GJB } \\
\text { indicating the } \\
\text { location of of } \\
\text { heaters. (c) SEM } \\
\text { image of the } \\
\text { head of the GJB } \\
\text { [7-8]. }\end{array}$ \\
(b)
\end{tabular}

developing a reliable method for initiating the flight and control the direction of flight of insects have remained a major limitation in the development of insect based MAV.

Recent advances in micro fabrication have made it possible for the researchers to make sensors weighing less than a gram that can be attached as a "backpack". Further, surgical implantation of microsystems in hawk moth was demonstrated by Paul et al. [910]. A permanently anchored base was created in an adult moth by inserting a biocompatible balsa titanium anchor in the late pupal stage of the moth.

This paper presents an effort at microthermal stimulation, which exploits the natural propensity of insects to escape fire, to initiate the flight and control the direction of beetles. The Green June beetle (GJB) of the genus 'Cotinis' and species 'Nitida' has active flight behavior and appreciable load capacity, which favors it as a biological carrier for multiple sensing applications (Fig. 1) [11]. It has been observed that the head of the beetle is most sensitive to thermal stimulation, particularly in the vicinity of the antennae [12]. This work explores the feasibility of both resistive and piezothermal stimulators and analyzes their relative performance. The present technique, while being less intrusive, is potentially widely applicable due to its independence from any specific neurological or physiological structures of the concerned insect. The following sections present the analytical model for thermal stimulation followed by device structure, fabrication technique, experimental results and finally the relevant discussion and conclusion.

\section{ANALYTICAL MODEL}

In the present analysis microthermal stimulators are mounted near the base of the antennae and are operated in appropriate sequence to stimulate the desired flight response. The beetle and the non-conductive epoxy (used to bond the thermal stimulator to the beetle surface) are assumed to be two semi-infinite bodies in thermal equilibrium with each other. The equilibrium temperature, $\mathrm{T}_{0}$ at the interface of these two semi-infinite bodies is given by [13]:

$$
T_{o}=\frac{T_{1} \sqrt{\rho_{1} c_{1} k_{1}}+T_{2} \sqrt{\rho_{2} c_{2} k_{2}}}{\sqrt{\rho_{1} c_{1} k_{1}}+\sqrt{\rho_{2} c_{2} k_{2}}}
$$

where, $\mathrm{T}_{1}, \mathrm{~T}_{2}$ are the temperatures of the first and the second semiinfinite bodies;

$\rho_{1}, \rho_{2}$ are the densities of the two bodies;

$\mathrm{c}_{1}, \mathrm{c}_{2}$ are the specific heat capacities of the two bodies, and

$\mathrm{k}_{1}, \mathrm{k}_{2}$ are the thermal conductivities of the two bodies.

Table 1: Properties of beetle shell and epoxy used in the analytical model.

\begin{tabular}{|l|l|}
\hline \multicolumn{1}{|c|}{ Beetle shell properties } & \multicolumn{1}{c|}{ Epoxy Properties } \\
\hline Initial Temp., $\mathrm{T}_{1}=300 \mathrm{~K}$ & Initial Temp., $\mathrm{T}_{2}=393 \mathrm{~K}$ \\
\hline Density, $\rho_{1}=1496 \mathrm{~kg} / \mathrm{m}^{3}$ & Density, $\rho_{2}=870 \mathrm{~kg} / \mathrm{m}^{3}$ \\
\hline Heat Capacity, $\mathrm{c}_{1}=$ & Heat Capacity, $\mathrm{c}_{2}=$ \\
$3700 \mathrm{~J} / \mathrm{kgK}$ & $1100 \mathrm{~J} / \mathrm{kgK}$ \\
\hline Thermal Conductivity, & Thermal Conductivity, $\mathrm{k}_{2}=$ \\
$\mathrm{k}_{1}=1 \mathrm{~W} / \mathrm{m} / \mathrm{K}$ & $0.25 \mathrm{~W} / \mathrm{m} / \mathrm{K}$ \\
\hline
\end{tabular}



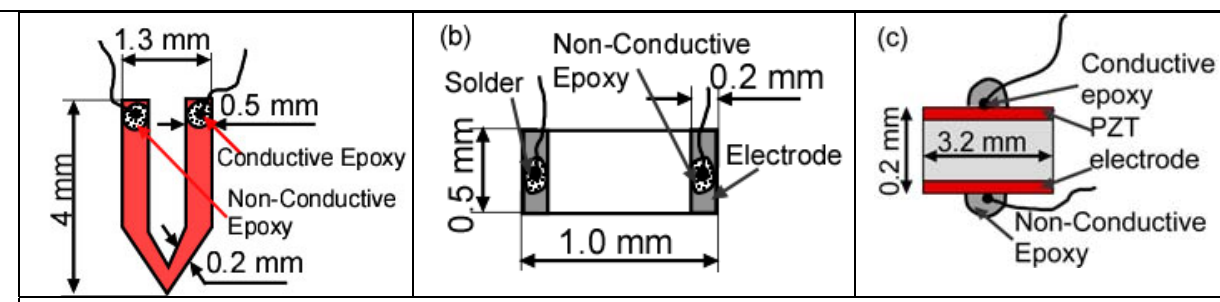

Fig. 2: Schematic of various thermal stimulators used for present study (Table 2): (a) UM_HTR1 (micromachined bulk Ni resistive stimulator); (b) HTR2 and HTR3 (surface mount resistors); (c) HTR4 (piezothermal disc).
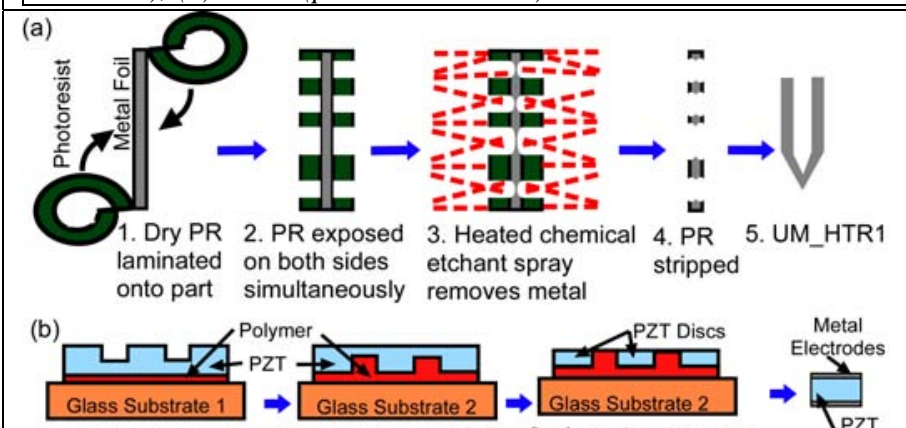

1. Bond a PZT
plate to a glass
substrate and USM

to pattern it. plate from Glass

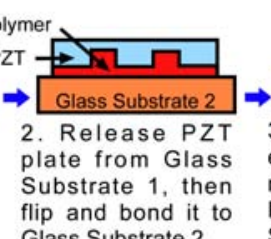

flip and bond it to
Glass Substrate 2 .
Fig. 3: (a) Fabrication of bulk $\mathrm{Ni}$ heater (UM_HTR1) - metal foil is covered with dry $P R$, which is used to mask spray etch (b) Piezothermal stimulator can be ultrasonically machined (USM) - PZT plate is ultrasonically patterned, which is subsequently lapped from back to get the piezo discs [14].

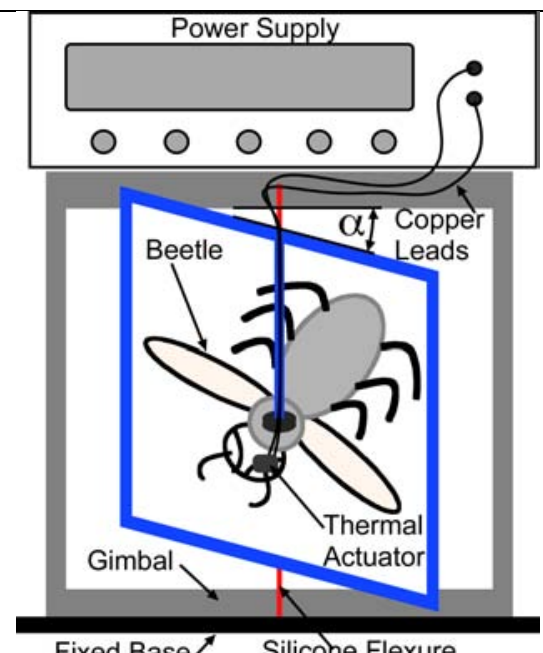

Fixed Base $\nearrow \quad$ Silicohe Flexure

Fig. 4: Experimental set-up with beetle mounted on the gimbal (with silicone flexure, torsional stiffness $=68.7 \mathrm{mN}$ $\mathrm{mm} / \mathrm{rad}$ ) and thermal stimulator attached near its left antenna. Thermal stimulation on the left side of the beetle makes it turn towards its right.

Table 2: Comparison chart for different types of thermal stimulators used in flight response characterization of green june beetle (GJB).

\begin{tabular}{|c|c|c|c|c|}
\hline & UM_HTR1 & HTR2 & HTR3 & HTR4 \\
\hline Description & $\begin{array}{l}\text { Micromachined bulk Ni } \\
\text { stimulator }\end{array}$ & Surface mount resistors & Surface mount resistors & Piezothermal stimulator \\
\hline Suffixes & $\begin{array}{l}\text { 'a' - in air } \\
\text { 'b' - bonded to beetle }\end{array}$ & $\begin{array}{l}\text { 'a' - in air } \\
\text { 'b' - bonded to beetle }\end{array}$ & $\begin{array}{l}\text { 'a' - in air } \\
\text { 'b' - bonded to beetle }\end{array}$ & $\begin{array}{l}\text { 'g' - bonded to glass } \\
\text { 'b' - bonded to beetle }\end{array}$ \\
\hline Dimensions & $4 \times 1.3 \times 0.05 \mathrm{~mm}^{3}$ & $1 \times 0.5 \times 0.35 \mathrm{~mm}^{3}$ & $1 \times 0.5 \times 0.35 \mathrm{~mm}^{3}$ & $\Phi=3.2 \mathrm{~mm} \mathrm{\&} \mathrm{thk.}=0.2 \mathrm{~mm}$ \\
\hline Electrical Prop. & Resistance $=2 \Omega$ & Resistance $=2.7 \Omega$ & Resistance $=24 \Omega$ & Capacitance $=0.65 \mathrm{nF}$ \\
\hline Mechanism & Resistive & Resistive & Resistive & Piezoelectric \\
\hline
\end{tabular}

The subscripts ' 1 ' and '2' refer to beetle shell and epoxy, respectively. The properties of these materials assumed for the analysis are given in Table 1 . The beetle-epoxy interface temperature generated by the stimulator was estimated to be $43^{\circ} \mathrm{C}$.

\section{DEVICE DESIGN AND FABRICATION}

Four different kinds of externally mounted microthermal stimulators were investigated: custom micro-machined bulk nickel resistive heaters (UM_HTR1), surface mount resistors (HTR2/3), and piezothermal PZT disks (HTR4) (Fig. 2, Table 2). Each of them was connected to the power supply through thin copper wire (gauge $\approx 38$, length $\approx 40 \mathrm{~cm}$, resistance $\approx 0.2 \Omega$ ).

UM_HTR1, the ' $V$ ' shaped bulk Ni heaters $\left(4 \times 1.3 \times 0.05 \mathrm{~mm}^{3}\right)$ were fabricated by laminating dry resist on both sides of a $\mathrm{Ni}$ sheet, patterning and spray etching it, followed by electrochemical polishing (Fig. 3a). In order to concentrate the thermal energy at the tip of the stimulator, an additional time etch step was performed to yield a thinned tip of the stimulator. (Some of these fabrication steps were outsourced.) Electrode wires were connected using conductive epoxy followed by an insulating layer of non-conductive epoxy. A fabricated device is shown in Fig. 5.

The rectangular surface mount resistors (Fig. 3c, Table 2), while being commercially available and compact in size $\left(1 \times 0.5 \times 0.35 \mathrm{~mm}^{3}\right)$, have limited options on resistance and dimensions. Electrode wires were soldered in place with Indalloy \#42 solder with an insulating layer of non-conductive epoxy.
Circular PZT devices $(\Phi=3.2 \mathrm{~mm} \&$ thickness $=0.2 \mathrm{~mm})$ were fabricated by ultrasonic machining from a PZT plate, followed by metallization (Fig. 3b). The fabrication of piezothermal stimulators was a two step process. The first step involved micromachining of steel tool using serial micro electro discharge machining [14]. In the next step, the pattern formed on this tool was transferred to the PZT-5H plate using ultrasonic machining with the help of tungsten carbide abrasive powder. The plate was then finally flipped over and lapped from behind to release the pattern imprinted by the steel tool. Electrode wires were connected to the PZT discs by using conductive epoxy followed by an insulating layer of non-conductive epoxy.

\section{EXPERIMENTAL RESULTS}

The response of the beetles was quantified by attaching them to a custom fabricated gimbal with an acrylic frame and silicone flexures (Fig. 4). The gimbal was designed such that it offers least resistance for rotation about its axis, while constraining the spatial movement. The torsional stiffness of the silicone flexures was experimentally measured to be $68.7 \mathrm{mN}-\mathrm{mm} / \mathrm{rad}$. The microthermal stimulators were mounted in close vicinity of the two antennae (Fig. 5). The stimulators were bonded using epoxy in order to prevent it from being dislodged by the beetle. A DC power supply (HP E3630A) and an AC function generator (HP $33520 \mathrm{~A}$ ) was used to actuate the resistive stimulators and piezothermal stimulators respectively. 


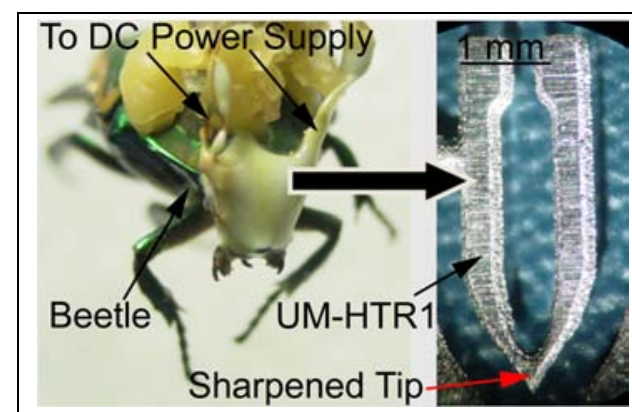

Fig. 5: Photograph of beetle with Ni resitive stimulators (UM_HTR1, Table 2) bonded near its antennae. The sharpened heater tip localizes stimulation.

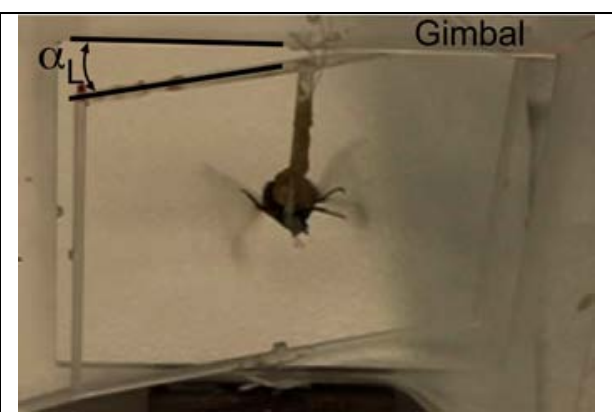

Fig. 6: Photograph of beetle turning towards its left due to thermal stimulation near its right antenna.

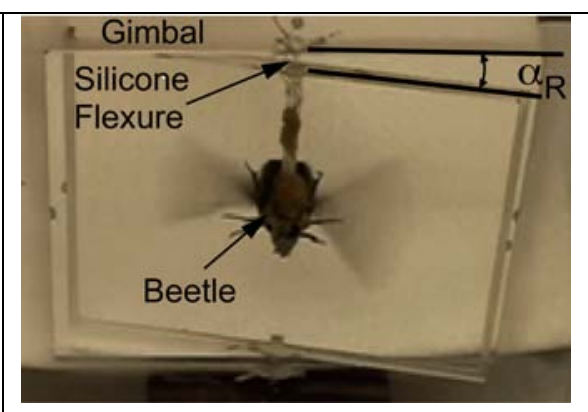

Fig. 7: Photograph of beetle turning towards its right due to thermal stimulation near its left antenna.
Preliminary results confirmed an aversion of beetle to the thermal stimulation. The microthermal stimulator UM_HTR1 repeatedly demonstrated flight initiation and directional control of the GJB when a voltage of $1.75 \mathrm{~V}$ was applied, resulting in an estimated temperature of $43^{\circ} \mathrm{C}$ at the beetle-heater interface (Fig. 6-7) [11]. The beetle turned away from the side being heated by approximately $15^{\circ}(0.26 \mathrm{rad})$, which resulted in a torque of $18 \mathrm{mN}$ $\mathrm{mm}$.

The maximum temperature attained and specific time constant (i.e., STC, the time constant per unit mass) were measured for various resistive and piezothermal stimulators (UM_HTR1 and HTR2/3/4), for different thermal boundary conditions: in air, on beetle and on glass substrate. Figure 8 shows the experimental setup used for characterizing various thermal stimulators. For the resistive stimulators, both the voltage and the current through the stimulator was measured using HP E3630A DC power supply. The power consumed was given by the product of voltage across the stimulator and the current flowing through it. Similarly, the voltage and current across the PZT was measured using an Agilent DSO6014A oscilloscope and Tektronix CT1 $(1 \mathrm{GHz})$ current probe respectively. The power dissipated by the PZT is given by:

$$
\mathrm{P}_{\mathrm{c}}=\mathrm{V}_{\mathrm{rms}} \mathrm{I}_{\mathrm{rms}} \cos (\varphi)
$$

where $\varphi$ is the phase difference between the current and the voltage obtained by measuring the difference in time axis between the maxima of voltage and the current signals. The temperatures in both experiments were measured using a K-type thermocouple read using HH506A multilogger thermometer.

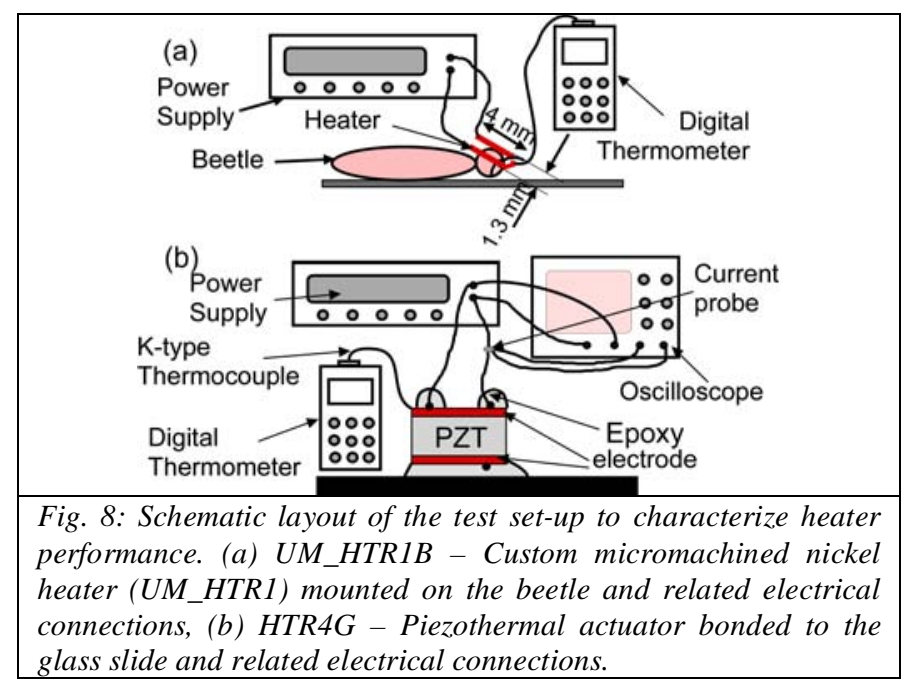

Figure 9 suggests that the thermal efficiency (temperature rise/power) for resistive stimulators improves with decrease in size and with increase in resistance of the stimulator. This is mainly due to the decrease in the power loss due to convection and the resistance of the connecting leads. The plot indicates that HTR3 is about 1.25 times as efficient as HTR2, considering the thermal performance of heaters in air.

Further, a similar analysis of the piezothemal stimulator, HTR4, suggests that it offers about three times greater efficiency than resistive micro stimulators. HTR4 is further investigated for optimal operating frequency to generate desired stimulation temperature. Figure 10 shows the steady state temperature attained by the bulk PZT assembly bonded to the exoskeleton of the beetle, as a function of the frequency of the sinusoidal voltage input. The frequency corresponding to the maximum temperature attained is then further used to generate a steady state response of the piezothermal stimulator for varying input power (Fig. 10). The existence of an optimal operating frequency of the piezothermal actuator is shown by the resonance peak observed in Fig. 10. This frequency $(650 \mathrm{kHz})$ corresponds to one of the resonance frequencies of the PZT structure measured using the impedance analyzer (Agilent 4395A). As expected, the system attains a maximum temperature at resonance frequency. Finally, the piezothermal stimulator is characterized for steady state thermal efficiency (temperature rise per milliwatt) attained at different frequencies (Fig. 11). Moreover, HTR4 achieves a maximum thermal efficiency of $0.93^{\circ} \mathrm{C} / \mathrm{mW}$ at $600 \mathrm{kHz}$, slightly below its resonance frequency $(650 \mathrm{kHz})$.

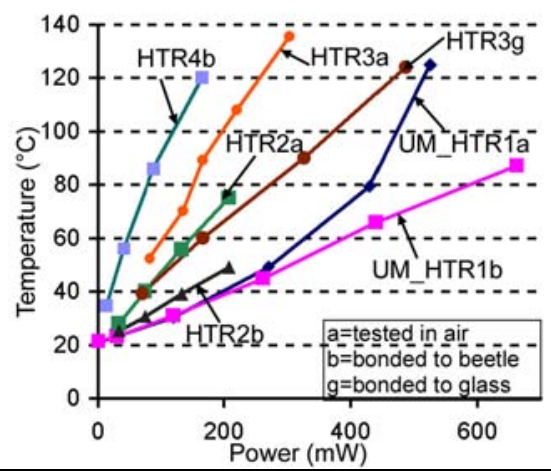

Fig. 9: Maximum temperatures attained by various stimulators for specified power inputs, with different thermal boundary conditions. Suffixes $a, b$ and $g$ denote air, beetle and glass slide substrate respectively. The voltage and current across the PZT was measured using an oscilloscope and current probe respectively. 


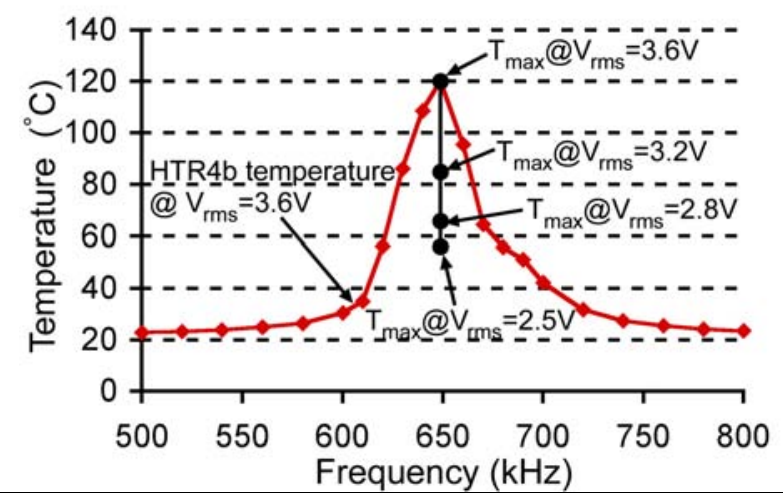

Fig. 10: Temperature generated by the piezothermal stimulator for different actuation frequencies. The piezothermal stimulator (HTR4b) shows a resonance at about $650 \mathrm{kHz}$ and achieves a maximum temperature of $120{ }^{\circ} \mathrm{C}$ at resonance. The maximum temperature attained at resonance frequency for various input voltages is also plotted.

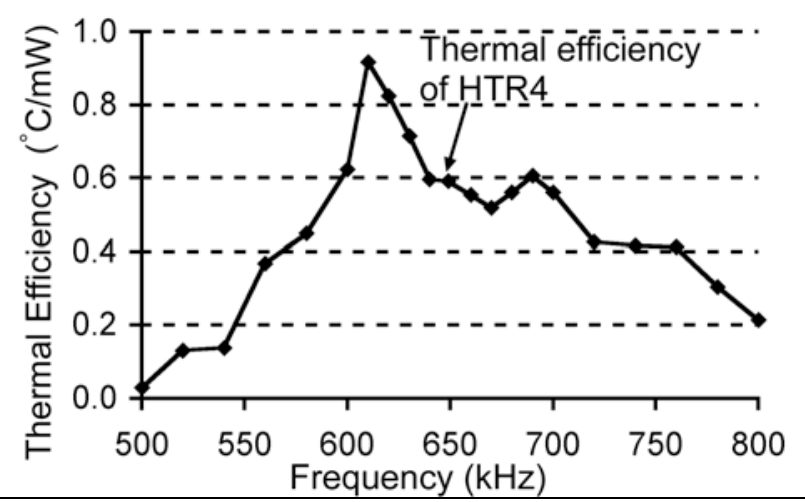

Fig. 11: The thermal efficiency (temperature rise/unit power) of HTR $4 b$ as a function of frequency of the sinusoidal input voltage. The thermal efficiency of the PZT stimulator was found to attain its maximum around $600 \mathrm{kHz}$.

Table 3: Specific time constant for various heating elements.

\begin{tabular}{|c|c|}
\hline Heating element & Specific time constant $(\mathbf{s e c} / \mathbf{m g})$ \\
\hline UM_HTR1b (on beetle) & 0.18 \\
\hline HTR2b (on beetle) & 0.22 \\
\hline HTR4b (on beetle) & 0.11 \\
\hline HTR3g (on glass) & 0.22 \\
\hline HTR4g (on glass) & 0.09 \\
\hline
\end{tabular}

The fundamental theoretical STC limits of various stimulators are also calculated. This determines the latency time for the beetle to respond to thermal stimulation. The STC of HTR4 is 90 $\mathrm{msec} / \mathrm{mg}$ as compared to $180 \mathrm{msec} / \mathrm{mg}$ for UM_HTR1 and 220 $\mathrm{msec} / \mathrm{mg}$ for HTR2/3 (Table 3). Apart from having a comparatively low STC, UM_HTR1 also provides more thermal localization than the surface mount stimulators. Further, its ' $\mathrm{V}$ 'shape is also easier to mount around the antenna making it most ideal for the experiment.

\section{CONCLUSION}

The study suggests that microthermal stimulation can be used as a reliable technique to initiate and control the flight of GJB. Both resistive and piezothermal stimulation appear to be feasible.
Piezothermal stimulation has lower specific time constant and proved to be more power efficient particularly around resonance, as compared to the resistive stimulators. Since the PZT has a Curie temperature of $350^{\circ} \mathrm{C}$, which is far in excess of the stimulation requirements, resonant piezothermal stimulation is very attractive for continuing efforts.

\section{ACKNOWLEDGEMENTS}

The authors would like to thanks Tao $\mathrm{Li}$ for his invaluable suggestions and Hirotaka Sato for his help in rearing the beetles. This study is supported in part by Defense Advanced Research Projects Agency Microsystems Technology office (DARPAMTO). YG acknowledges support through the IR/D program while working at the National Science Foundation. The findings do not necessarily reflect the views of the NSF. KV acknowledges partial support by a fellowship from the Mechanical engineering department.

\section{REFERENCES}

[1] K. Hausen, C. Wehrhahn, "Neural Circuits Mediating Visual Flight Control in Flies. I. Quantitative Comparison of Neural and Behavioural Response Characteristics," Journal of Neuroscience, 9 (11), 1989.

[2] K. Hausen, C. Wehrhahn, "Neural Circuits Mediating Visual Flight Control in Flies. II.Separation of Two Control Systems by Microsurgical Brain Lesions," Journal of Neuroscience, 10 (1), 1990.

[3] S.P. Sane, A. Dieudonne, M.A. Willis, T.L. Daniel, "Antennal Mechanosensors Mediate Flight Control in Moths," Science, 315, 2007.

[4] H. Sato, C.W. Berry, B.E. Casey, G. Lavella, Y.Yao, J.M. VandenBrooks, M.M. Maharbiz, "A Cyborg Beetle: Insect Flight Control Through an Implantable Tetherless Microsystem," IEEE MEMS, Tucson, USA, Jan. 2008, pp. 164-167

[5] S. B. Crary, T. E. Moore, T. A. Conklin, F. Sukardi, and D. E . Koditschek, "Insect biobotics: Electro-neural control of cockroach walking," IEEE Robotics and Auto-mation workshop WT3, BioMechatronics, 1996, pp. 42-54.

[6] S. Takeuchi, I. Shimoyama, "An RF- Telemetry System with Shape Memory Alloy Microelectrodes for Neural recording of Freely Moving Insects," IEEE Special Topic Conf. on Microtech. in Medicine \& Biology, 2000, pp. 491-96,

[7] http://www.uglybug.org/images02/bug69.jpg, accessed on $3^{\text {rd }}$ March 2008

[8] http://redwhisk.com/pictures/longwoodgardens/july2006/dsc_ 0082a_greenjunebeetle.jpg, accessed on 3rd March 2008

[9] A. Paul, A. Bozkurt, J. Ewer, B. Blossey, A. Lal, "Surgically Implanted Micro-platforms in Manduca Sextamoth," 2006 SolidState Sensor \& Actuator Workshop, Hilton Head, SC, pp. 209-211 [10] A. Lal, Hybrid Insect MEMS, http://www.darpa.mil/MTO/ Programs/himems/index.html

[11] J. M. Domek, D. T. Johnson, "Demonstration of Semio chemically Induced Aggregation in Green June Beetle, Cotinis Nitida," Environmental Entomology, 17 (2),1988

[12] P. J. Gullan, P. Cranston, "The Insects: An Outline of Entomology," Blackwell Publishing, 2004, pp. 85-111.

[13] Y. A. Cengel, "Heat Transfer - A Practical Approach," McGraw Hill, 1997, pp. 244-271.

[14] T. Li. Y. B. Gianchandani, "A Micromachining Process for Die- scale Pattern Transfer in Ceramics and its Application to Bulk Piezoelectric Actuators," JMEMS, 15 (3), 2006. 